\title{
Barriers and facilitators to primary health care for people with intellectual disabilities and/or autism: an integrative review
}

\author{
Alison Jayne Doherty ${ }^{1 *}$, Helen Atherton ${ }^{2}$, Paul Boland ${ }^{1}$, Richard Hastings ${ }^{2}$, \\ Lucy Hives ${ }^{1}$, Kerry Hood ${ }^{3}$, Lynn James-Jenkinson ${ }^{4}$, Ralph Leavey ${ }^{1}$, \\ Elizabeth Randell ${ }^{3}$, Janet Reed ${ }^{1}$, Laurence Taggart ${ }^{5}$, Neil Wilson ${ }^{1}$, \\ Umesh Chauhan ${ }^{1}$
}

${ }^{1}$ University of Central Lancashire, Preston, UK; ${ }^{2}$ University of Warwick, Coventry, UK; ${ }^{3}$ Cardiff University, Cardiff, UK; ${ }^{4}$ Pathways Associates (CIC), Accrington, UK; ${ }^{5}$ Ulster University, Coleraine, UK

*For correspondence: adoherty7@uclan.ac.uk

Competing interest: The authors declare that no competing interests exist.

Received: 23 October 2019 Accepted: 23 October 2019 Published: 01 July 2020

(C)This article is Open Access: CC BY license (https://creativecommons.org/licenses/by/4.0/)

Author Keywords: intellectual disability, autistic disorder, review, barriers, facilitators, primary health care, general practice

Copyright (C) 2020, The Authors; DOI:10.3399/

bjgpopen20X101030

\begin{abstract}
Background: Globally, people with intellectual disabilities and/or autism experience health inequalities. Death occurs at a younger age and the prevalence of long-term morbidities is higher than in the general population. Despite this, their primary healthcare access rates are lower than the general population, their health needs are often unmet, and their views and experiences are frequently overlooked in research, policy, and practice.
\end{abstract}

Aim: To investigate the barriers and facilitators reported by individuals with intellectual disabilities, autism, or both, and/or their carers, to accessing and utilising primary health care for their physical and mental health needs.

Design \& setting: An integrative review was undertaken, which used systematic review methodology.

Method: Electronic databases MEDLINE, Embase, CINAHL (Cumulative Index to Nursing and Allied Health Literature), and Cochrane were searched for relevant studies (all languages) using a search strategy. Two researchers independently screened the results and assessed the quality of the studies.

Results: Sixty-three international studies were identified. Six main themes relating to barriers and facilitators emerged from an analysis of these studies. The main themes were: training; knowledge and awareness; communication; fear and embarrassment; involvement in healthcare decision-making; and time. All the themes were underpinned by the need for greater care, dignity, respect, collaborative relationships, and reasonable adjustments. Opposing barriers and facilitators were identified within each of the main themes.

Conclusion: Adolescents and adults with intellectual disabilities and/or autism experience several barriers to accessing and utilising primary health care. The findings highlight the reasonable adjustments and facilitators that can be implemented to ensure that these individuals are not excluded from primary health care.

\section{How this fits in}

This review synthesises evidence on the barriers and facilitators to accessing and utilising primary health care perceived by people with intellectual disabilities and/or autism. The findings highlight important considerations for primary healthcare policy, practice, and further research. 


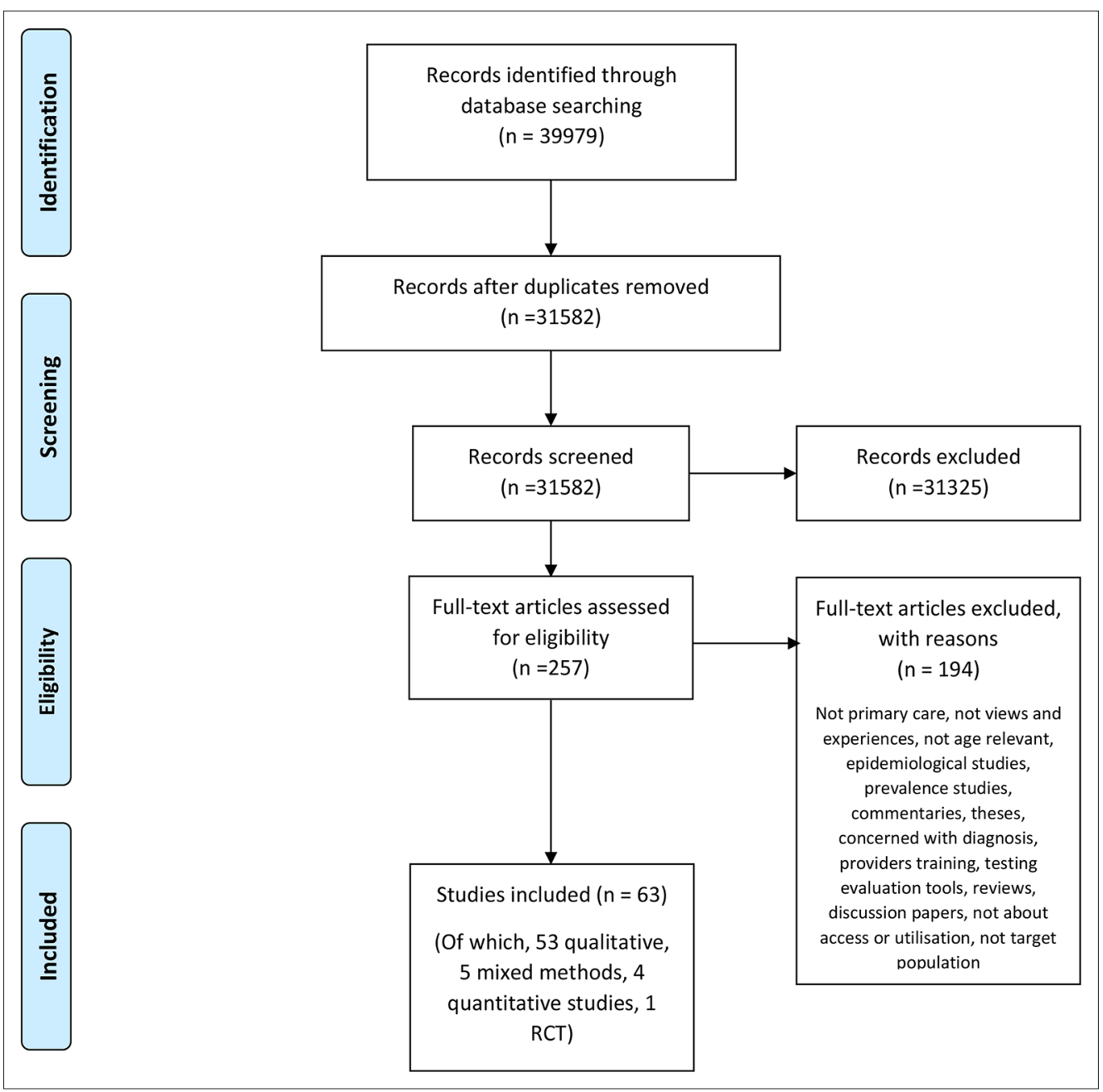

Figure 1 PRISMA diagram illustrating the literature search strategy. RCT = randomised controlled trial.

\section{Introduction}

People with intellectual disabilities and/or autism experience health inequalities. ${ }^{1,2}$ Death occurs at a younger age and the prevalence of long-term morbidities is higher than in the general population. ${ }^{2}$ UK guidance outlines the necessity of tailoring healthcare services to meet their needs. ${ }^{3}$ Despite this, their access to healthcare services is lower than the general population, ${ }^{4,5}$ their health needs are often unrecognised or unmet, ${ }^{6}$ and their views and experiences are frequently overlooked. ${ }^{7,8}$

While previous reviews have investigated healthcare-access issues for people with intellectual disability, ${ }^{9,10}$ a recent mapping of the health and wellbeing needs of adults with both intellectual disability and autism identified an absence of research to determine their needs. ${ }^{11}$ This lack of understanding represents a significant knowledge gap in efforts to improve their health and wellbeing. There may be overlap between these groups, but their needs may be unique and nuanced. ${ }^{11}$

The aim of this study was to identify and synthesise evidence concerning the barriers and facilitators experienced by adolescents and adults with intellectual disabilities (only), autism (only), or both, and/ or their carers, to accessing and/or utilising primary health care for their physical and mental health needs.

\section{Method}

The integrative review (utilising systematic review methodology) was conducted according to a prespecified protocol and written in accordance with the Preferred Reporting Items for Systematic Reviews and Meta-Analyses (PRISMA) 2009 checklist and reporting standards (Figure 1). ${ }^{12}$ The search strategy 
is contained within the registered protocol. Electronic databases were searched using key terms and $\mathrm{MeSH}$ headings combined. The databases used were: Ovid Medline (up to 22 August 2018); Embase (22 August 2018); CINAHL Complete (22 August 2018); and Cochrane (22 August 2018).

Studies were eligible if they were: studies of any design; and included people aged $\geq 14$ years (eligible for annual health checks in UK) who were formally identified, or self-identified, as having an intellectual disability and/or autism, and their family members, carers, support workers, and/ or healthcare professionals. Studies were also eligible that explored access to health care for any physical and/or mental health conditions involving the target population. The studies could be from any primary healthcare setting; for example, GP practices and other providers, pharmacies, dental surgeries, ophthalmic services, and screening and immunisation services. Studies included primary healthcare services in the UK and in other countries with similarly structured, funded, and resourced services. Eligible studies were published in all languages between 2001 and 2018. These publication dates were not stated in the study protocol. Studies conducted before 2001 were excluded owing to legislative changes introduced for the target population, including the Department of Health and Social Care's Valuing People - A New Strategy for Learning Disability for the 21st Century, published in 2001. ${ }^{13}$ Systematic reviews, book reviews, editorials, commentaries, epidemiological studies, and prevalence studies were excluded.

'Access to health care' in this review is concerned with helping people to command appropriate healthcare resources to preserve or improve their health, and 'equity of access' is considered in terms of availability, utilisation, or service outcomes. ${ }^{14,15}$

Titles and abstracts were first screened for relevance independently by two researchers. Three researchers independently read and assessed the full texts of relevant citations, using the pre-specified eligibility criteria. Any citation queries were discussed by the three researchers and a consensus decision reached to resolve any queries.

Study quality was assessed independently by two researchers using the Mixed Methods Analysis Tool (MMAT). ${ }^{16,17}$ The MMAT is designed for use in the appraisal stage of systematic reviews of different types of studies. The critical appraisal of studies considered issues such as the appropriateness of the study's design to the study's research objective. This was used to provide context for the findings of the study. The two researchers independently assessed the number of criteria met by each study in each of the MMAT's domains of assessment ${ }^{17}$ and provided each study with a score. Studies were

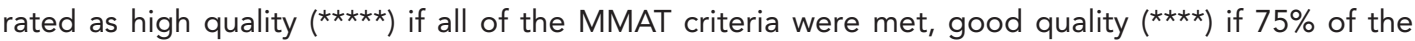
criteria were met, satisfactory $\left(^{* \star *}\right)$ if $50 \%$ of the criteria were met, poor $\left.{ }^{* \star}\right)$ if the study met $25 \%$ of the criteria, and very poor $\left(^{*}\right)$ if the study met $<25 \%$ of the MMAT scoring criteria. The researchers' independent appraisal findings were compared and agreed. Any queries over studies' appraisals were discussed with two other independent researchers to reach a consensus decision.

Data were extracted from the included studies using a data extraction tool, which was specifically designed and piloted by the research team. The data from the included studies were analysed using thematic analysis. ${ }^{18}$ Two researchers independently developed the themes. These themes were compared, key themes agreed, and narratively synthesised by the two researchers. A third reviewer was involved where necessary. NVivo (version 12) supported the data analysis.

\section{Results}

Sixty-three studies met the eligibility criteria for inclusion in the review. The review identified 53 qualitative studies, five mixed-methods studies, four quantitative studies, and one randomised controlled trial. Twenty-four studies were conducted between the years 2003 and 2010, and 39 studies were conducted between 2011 and 2018. Most studies were conducted in the UK ( $n=33)$, the US ( $n$ $=13)$, and Australia $(n=8)$. Forty-nine studies explored the views and experiences of participants with intellectual disabilities, 13 studies explored the views and experiences of participants with autism, and one study explored the views and experiences of participants with both intellectual disabilities and autism.

\section{Quality of studies}

Of the 63 eligible studies, 46 (73\%) were rated as high quality, two were rated as good quality, seven were rated as being either satisfactory, poor, or very poor, and eight were not rated owing to their lack 
of reported information. However, none of the studies were excluded from the review as any appraisal process is potentially only evaluating the reporting of the study rather than its actual conduct and content, which may usefully inform the findings and discussion. ${ }^{19}$

\section{Themes}

Six common themes were identified by the thematic analysis. Participants perceived of barriers and facilitators within each of these themes as being integrated in an opposing fashion, as narratively discussed below.

\section{Training}

Healthcare providers (both primary and acute health care) may lack specialist training in this field. ${ }^{20-22}$ Barriers to their training include time constraints, knowledge gaps, and uncertainties over specialist help. ${ }^{23}$ Despite this, healthcare providers recognise the importance of such specialist training for people with intellectual disabilities and for others with communication challenges. ${ }^{23}$ Training, knowledge, and awareness-raising for healthcare providers, family members, carers, and support services is essential; ${ }^{24}$ for example, training for healthcare providers in communicating with people who have intellectual disabilities and/or autism. ${ }^{25}$ People with intellectual disabilities should be included in the training of healthcare providers as 'experts by experience'. ${ }^{25-27}$ However, while such training may be essential, it may not be routinely undertaken owing to resource constraints. ${ }^{22}$

\section{Knowledge and awareness}

Some healthcare providers may lack understanding, knowledge, and awareness about to how to support people with autism and intellectual disabilities, ${ }^{28-30}$ including how to make appropriate reasonable adjustments. ${ }^{29}$ This lack of knowledge and understanding may lead to poor attitudes, such as an abrupt way of speaking or coldness towards people with autism or intellectual disabilities. Poor attitudes held by both healthcare professionals and non-health professionals, across both primary and acute healthcare provider settings, is a recurring theme in the review's identified studies. ${ }^{22,31-33}$ A warm, friendly, and caring attitude from healthcare providers enables service users to access healthcare facilities and discuss sensitive health concerns. ${ }^{22,34-37}$

\section{Communication}

Communication is a significant barrier for people with autism and/or intellectual disabilities. ${ }^{29,38-42} \mathrm{It}$ causes problems in primary care as inadequate communication can result in the wrong diagnosis and inappropriate medication, and it can prevent a person's access to receiving adequate health care. ${ }^{23,43,44}$ Studies found a lack of awareness by healthcare providers about the range of communication issues faced by people with intellectual disabilities and/or autism when accessing and attending primary and acute healthcare settings. ${ }^{23,45-47}$ Healthcare practitioners may rely on communicating with a carer, family member, or support worker rather than with the service user directly. ${ }^{23,25,36,45,47}$ Carers do not always allow the service user to speak for themselves or carers might try to protect them from perceived harmful communication, ${ }^{28}$ thereby preventing service users from exerting control over their own healthcare needs. ${ }^{32}$ Not being listened to created anxiety for some service users with intellectual disabilities and/or autism. ${ }^{48}$

Good communication between the healthcare provider and the patient with autism and/or an intellectual disability is vital when accessing and utilising health care. ${ }^{48,49}$ If these patients find health care stressful because of poor communication then they may lower their expectations, lower their attendance, and feel disaffected, and this may lead to ineffective health care. ${ }^{23}$

Some healthcare information may be incomprehensible and/or difficult to obtain. ${ }^{25,34,50,51}$ Accessible healthcare information is perceived to be a high priority by people with intellectual disabilities and/or autism. ${ }^{48-50}$ The use of easy-read information, sign language, non-face-to-face communication, such as via the telephone, not overloading the service user with verbal information, and use of virtual reality have been suggested as preferred methods of communication for this population. ${ }^{26,52}$

The ability to see the same healthcare professional is important for people with intellectual disabilities and/or autism. ${ }^{34}$ This notion is also shared by healthcare professionals themselves, with suggestions that this would provide the opportunity to gain a better understanding of the medical history and communication style of the service user. ${ }^{36}$ Being treated with dignity and respect and 
being valued by healthcare providers are key facilitators, ${ }^{47,53}$ and are important in forming good relationships. ${ }^{54}$ Collaborations between health and other social care providers are also essential. ${ }^{55,56}$

\section{Fear and embarrassment}

Fear and embarrassment is a barrier to accessing health care for individuals with intellectual disabilities and/or autism. ${ }^{57-59}$ These include fears of being judged over lifestyle choices, of blood tests and vaccinations, ${ }^{38}$ of medical instruments, ${ }^{31}$ and fears associated with a lack of understanding about screening procedures. ${ }^{59}$ Physical examinations can also be a source of embarrassment and/or discomfort for individuals with intellectual disabilities. ${ }^{38,60-63}$ Some people with intellectual disabilities and/or autism find the clinical environment daunting, ${ }^{63,64}$ owing to unpleasant or alarming noises, odours, and bright lights. ${ }^{31,65}$ The waiting room may induce anxiety, especially if the individual is unsure of why they are there. ${ }^{32}$ Facilitators, in terms of reasonable adjustments in the clinical environment, may include easy-read information, coloured pictures, models, photos, videos, symbols, and demonstration dolls. ${ }^{13,36,48,65}$

\section{Lack of involvement in healthcare decision-making}

People with intellectual disabilities and/or autism can make choices about their everyday lives, yet decisions about their health care may be made by their families, carers, and healthcare providers instead. ${ }^{25}$ Their involvement in the decision-making process is an essential part of their health care. ${ }^{13,34}$ They feel empowered when they are involved in the decision-making process and gain a better understanding of their treatment and diagnosis. ${ }^{28,66}$

People with intellectual disabilities and/or autism value healthcare professionals, their support network, and other professionals who work closely with them and who have specialist knowledge and experience of working with people who have intellectual disabilities. ${ }^{26,67-72} \mathrm{~A}$ joined-up approach, in which the sharing of inter-agency information is key, may help alleviate service users' healthcare fears. $^{26,36}$ Tailored services, which are person-centred, flexible, and family-centred, are highly regarded. ${ }^{26,72-77}$

\section{Time}

Prolonged times waiting to be seen and limited time spent with a healthcare professional during an appointment act as barriers. Long waiting times are a major cause of anxiety and stress. ${ }^{25,32,45,78,79}$ Additional time is often required for effective communication with people who have intellectual disabilities and/or autism. ${ }^{31,36,47,48}$ However, despite recognising the importance of spending time getting to know the service user, some healthcare providers can struggle to find extra time to achieve this familiarisation. ${ }^{22}$

\section{Discussion}

\section{Summary}

A lack of specialist training in both primary and acute health care is an important barrier, which may mean that healthcare providers lack knowledge and awareness of the healthcare needs of people with intellectual disabilities and/or autism. This may be associated with poor communication between such healthcare providers and service users, and a lack of involvement in healthcare decision-making processes for these service users. Effective communication delivered by specialist trained, friendly, and caring healthcare providers who treat service users with dignity is essential. Primary healthcare providers need to provide more accessible health-related information for service users (both in terms of availability and format), shorter waiting times and longer consultation times, less daunting clinical environments, improved consistency of care, and greater multidisciplinary collaborative working. This may help to improve the health and wellbeing of people with intellectual disabilities and/or autism. Improving these issues could help alleviate some of the fears reported by service users, which represent another reported barrier. However, the challenges involved in responding to these identified issues are acknowledged given that primary healthcare services in the UK are currently under intense resourcing pressures. ${ }^{80}$ 


\section{Strengths and limitations}

A strength of this review is that it provides a timely summary of the recent literature from 2001-2018. The review, importantly, included the views and experiences of people with intellectual disabilities and/or autism, and their families or carers, as well as healthcare professionals. It synthesised different types of studies using a rigorous methodology. However, a search of other relevant databases, such as PsycINFO, grey literature (including guidance and policy documents), and checking the references and citations of included studies, may have yielded additional results. Searches of grey literature and the checking of reference lists and citations for included studies were not undertaken, as originally stated in the study protocol, owing to staffing resource constraints.

Most of the identified studies were conducted in high-income countries (HICs) and may not reflect the views and experiences of people with intellectual disabilities and/or autism from low- and middleincome countries. Findings are not generalisable to all HICs either, as the review included studies from $\mathrm{HICs}$ such as the US, with different funding and organisational arrangements. The review was limited to studies involving individuals with intellectual disabilities and/or autism who were aged $\geq 14$ years. There may be transferable evidence from studies involving children and younger people from this population and other cognitive disability populations (for example, patients with dementia, cerebral palsy, stroke, or acquired brain injury). The use of convenience samples ${ }^{23,56}$ and self-selection ${ }^{20}$ may also bias the results. Some studies were limited to urban areas as opposed to rural areas, which may pose different healthcare barriers. ${ }^{81,82}$

\section{Comparison with existing literature}

To the authors' knowledge, this is the first integrative review of barriers and facilitators to accessing and utilising primary health care experienced by adolescents and adults with intellectual disabilities and/or autism. The review's findings are consistent with available UK guidance for GPs and other primary healthcare professionals, which outline the need to tailor primary care services for people with intellectual disabilities. ${ }^{3}$

\section{Implications for research and practice}

The review's findings highlight the reasonable adjustments and other modifications that could be implemented to ensure that people with intellectual disabilities and/or autism are not excluded from primary healthcare research and practice. Despite the constraints facing primary healthcare services in countries such as the UK, their contributions are crucial in addressing the health inequalities experienced by this population.

\section{Funding}

This study was funded by the Lancashire Research Institute for Global Health \& Wellbeing (LIFE), University of Central Lancashire (reference number: LIFE-IAMPAL0518). Alison Jayne Doherty was part-funded by the National Institute for Health Research (NIHR) Applied Research Collaboration North West Coast. The views expressed are those of the authors and not necessarily those of the NIHR or the Department of Health and Social Care.

\section{Ethical approval}

This was a systematic review which did not require specific ethical approval.

Trial registration number

PROSPERO: CRD42018103103.

Provenance

Freely submitted; externally peer reviewed.

\section{References}

1. Hatton C, Emerson E. Introduction: Health disparities, health inequity, and people with intellectual disabilities. In: Hatton C, Emerson E, eds. International Review of Research in Developmental Disabilities. Waltham, MA: Academic Press; 2015. 1-9. 
2. Heslop $P$, Blair PS, Fleming $P$, et al. The Confidential Inquiry into premature deaths of people with intellectual disabilities in the UK: a population-based study. Lancet 2014; 383(9920): 889-895. DOI: https://doi.org/10.1016/ S0140-6736(13)62026-7

3. Royal College of General Practitioners. Care of people with intellectual disability; https://www.gponline.com/rcgpcurriculum/care-of-people-with-learning-disabilities (accessed 24 Jun 2020).

4. Emerson E, Baines S. Health inequalities and people with learning disabilities in the UK: 2010. 2010; https:// pureportal.strath.ac.uk/files-asset/7402206/vid_7479_IHaL2010_3Healthlnequality2010.pdf (accessed 17 Jun 2020).

5. Felce $\mathrm{D}, \mathrm{Baxter} \mathrm{H}$, Lowe $\mathrm{K}$, et al. The impact of checking the health of adults with intellectual disabilities on primary care consultation rates, health promotion and contact with specialists. J Appl Res Intellect Disabil 2008; 21(6): 597-602. DOI: https://doi.org/10.1111/j.1468-3148.2008.00432.x

6. Byrne JH, Lennox NG, Ware RS. Systematic review and meta-analysis of primary healthcare interventions on health actions in people with intellectual disability. Journal of Intellectual and Developmental Disability 2016; 41(1): 66-74. DOI: https://doi.org/10.3109/13668250.2015.1105939

7. Walmsley J, Johnson K. Inclusive Research with People with Learning Disabilities: Past, Present and Futures. London: Jessica Kingsley; 2003.

8. Griffith GM, Hutchinson L, Hastings RP. "I'm not a patient, I'm a person": the experiences of individuals with intellectual disabilities and challenging behavior - a thematic synthesis of qualitative studies. Clin Psychol 2013: 20(4): 469-488.

9. Alborz A, McNally R, Glendinning C. Access to health care for people with learning disabilities in the UK: mapping the issues and reviewing the evidence. J Health Serv Res Policy 2005; 10(3): 173-182. DOI: https://doi.org/10. $1258 / 1355819054338997$

10. Krahn GL, Hammond L, Turner A. A cascade of disparities: health and health care access for people with intellectual disabilities. Ment Retard Dev Disabil Res Rev 2006; 12(1): 70-82. DOI: https://doi.org/10.1002/mrdd.20098

11. van Dooren K, McPherson L, Lennox N. Mapping the needs of adults with autism and co-morbid intellectual disability. Curr Dev Disord Rep 2016; 3(1): 82-89. DOI: https://doi.org/10.1007/s40474-016-0071-0

12. Higgins J, Green S. Cochrane Handbook for Systematic Reviews of Interventions. 2019; https://training.cochrane. org/handbook (accessed 17 Jun 2020).

13. Department of Health and Social Care. Valuing People - A New Strategy for Learning Disability for the 21st Century [Policy paper]. 2001; https://www.gov.uk/government/publications/valuing-people-a-new-strategy-forlearning-disability-for-the-21st-century (accessed 24 Jun 2020).

14. Gulliford M, Figueroa-Munoz J, Morgan M, et al. What does 'access to health care' mean? J Health Serv Res Policy 2002; 7(3): 186-188. DOI: https://doi.org/10.1258/135581902760082517

15. Levesque J-F, Harris MF, Russell G. Patient-centred access to health care: conceptualising access at the interface of health systems and populations. Int J Equity Health 2013; 12(1): 18. DOI: https://doi.org/10.1186/1475-9276-1218

16. Pluye $P$, Gagnon M-P, Griffiths F, et al. A scoring system for appraising mixed methods research, and concomitantly appraising qualitative, quantitative and mixed methods primary studies in mixed studies reviews. Int J Nurs Stud 2009; 46(4): 529-546. DOI: https://doi.org/10.1016/j.ijnurstu.2009.01.009

17. Hong QN, Fàbregues S, Bartlett $\mathrm{G}$, et al. The mixed methods appraisal tool (MMAT) version 2018 for information professionals and researchers. Education for Information 2018; 34(4): 285-291. DOI: https://doi.org/10.3233/EFI180221

18. Thomas J, Harden A. Methods for the thematic synthesis of qualitative research in systematic reviews. BMC Med Res Methodol 2008; 8(1): 45. DOI: https://doi.org/10.1186/1471-2288-8-45

19. Carroll C, Booth A. Quality assessment of qualitative evidence for systematic review and synthesis: is it meaningful, and if so, how should it be performed? Res Synth Methods 2015; 6(2): 149-154. DOI: https://doi.org/10.1002/jrsm. 1128

20. Brookman-Frazee L, Baker-Ericzén $M$, Stadnick N, et al. Parent perspectives on community mental health services for children with autism spectrum disorders. J Child Fam Stud 2012; 21(4): 533-544. DOI: https://doi.org/10.1007/ s10826-011-9506-8

21. McGillivray JA, McCabe MP. Detecting and treating depression in people with mild intellectual disability: the views of key stakeholders. Br J Learn Disabil 2010; 38(1): 68-76. DOI: https://doi.org/10.1111/j.1468-3156.2009.00573.x

22. Kroese BS, Rose J, Heer K, et al. Mental health services for adults with intellectual disabilities - what do service users and staff think of them? J Appl Res Intellect Disabil 2013; 26(1): 3-13. DOI: https://doi.org/10.1111/jar.12007

23. Murphy J. Perceptions of communication between people with communication disability and general practice staff. Health Expect 2006; 9(1): 49-59. DOI: https://doi.org/10.1111/j.1369-7625.2006.00366.x

24. Hemmings $\mathrm{C}$, Underwood L, Bouras $\mathrm{N}$. What should community services provide for adults with psychosis and learning disabilities? A comparison of the views of service users, carers and professionals. Advances in Mental Health and Learning Disabilities 2009; 3(3): 22-27. DOI: https://doi.org/10.1108/17530180200900027

25. Perry J, Felce D, Kerr M, et al. Contact with primary care: the experience of people with intellectual disabilities. $J$ Appl Res Intellect Disabil 2014; 27(3): 200-211. DOI: https://doi.org/10.1111/jar.12072

26. Weise J, Fisher KR, Whittle $\mathrm{E}$, et al. What can the experiences of people with an intellectual disability tell us about the desirable attributes of a mental health professional? J Ment Health Res Intellect Disabil 2018; 11(3): 183-202. DOI: https://doi.org/10.1080/19315864.2018.1469700

27. Weise J, Fisher KR, Trollor JN. What makes generalist mental health professionals effective when working with people with an intellectual disability? A family member and support person perspective. J Appl Res Intellect Disabil 2018; 31(3): 413-422. DOI: https://doi.org/10.1111/jar.12420 
28. Flynn S, Hulbert-Williams NJ, Hulbert-Williams L, et al. "You don't know what's wrong with you": an exploration of cancer-related experiences in people with an intellectual disability. Psychooncology 2016; 25(10): 1198-1205. DOI: https://doi.org/10.1002/pon.4211

29. lacono T, Humphreys J, Davis R, et al. Health care service provision for country people with developmental disability: an Australian perspective. Res Dev Disabil 2004; 25(3): 265-284. DOI: https://doi.org/10.1016/j.ridd. 2003.09.001

30. Barber C. Old age and people on the autism spectrum: a focus group perspective. Br J Nurs 2015; 24(21): 1054-1057. DOI: https://doi.org/10.12968/bjon.2015.24.21.1054

31. Blaizot $A$, Hamel $O$, Folliguet $M$, et al. Could ethical tensions in oral healthcare management revealed by adults with intellectual disabilities and caregivers explain unmet oral health needs? Participatory research with focus groups. $J$ Appl Res Intellect Disabil 2017; 30(1): 172-187. DOI: https://doi.org/10.1111/jar.12231

32. Jones MC, McLafferty E, Walley R, et al. Inclusion in primary care for people with intellectual disabilities: gaining the perspective of service user and supporting social care staff. J Intellect Disabil 2008; 12(2): 93-109.

33. Chaplin $E$, Halls $S$, Carlile $G$, et al. Barriers to user involvement in mental health services for people with learning disability. Advances in Mental Health and Learning Disabilities 2009; 3(3): 28-33. DOI: https://doi.org/10.1108/ 17530180200900028

34. Ryan S, Hislop J, Ziebland S. Do we all agree what "good health care" looks like? Views from those who are "seldom heard" in health research, policy and service improvement. Health Expect 2017; 20(5): 878-885. DOI: https://doi.org/10.1111/hex.12528

35. Michell B. Checking up on Des: my life my choice's research into annual health checks for people with learning disabilities in Oxfordshire. Br J Learn Disabil 2012; 40(2): 152-161. DOI: https://doi.org/10.1111/j.1468-3156.2012. 00742.x

36. Ziviani $\mathrm{J}$, Lennox $\mathrm{N}$, Allison $\mathrm{H}$, et al. Meeting in the middle: improving communication in primary health care consultations with people with an intellectual disability. J Intellect Dev Disabil 2004; 29(3): 211-225. DOI: https:// doi.org/10.1080/13668250412331285163

37. Gibbons HM, Owen R, Heller T. Perceptions of health and healthcare of people with intellectual and developmental disabilities in Medicaid managed care. Intellect Dev Disabil 2016; 54(2): 94-105. DOI: https://doi.org/10.1352/ 1934-9556-54.2.94

38. Turk V, Kerry S, Corney R, et al. Why some adults with intellectual disability consult their general practitioner more than others. J Intellect Disabil Res 2010; 54(9): 833-842. DOI: https://doi.org/10.1111/j.1365-2788.2010.01312.x

39. Vogan V, Lake JK, Tint A, et al. Tracking health care service use and the experiences of adults with autism spectrum disorder without intellectual disability: a longitudinal study of service rates, barriers and satisfaction. Disabil Health J 2017; 10(2): 264-270. DOI: https://doi.org/10.1016/j.dhjo.2016.11.002

40. Chan J, Hudson C, Vulic C. Services for adults with intellectual disability and mental illness: are we getting it right? Australian e-Journal for the Advancement of Mental Health 2004; 3(1): 24-29. DOI: https://doi.org/10.5172/jamh.3. 1.24

41. Hubert J. Family carers' views of services for people with learning disabilities from Black and minority ethnic groups: a qualitative study of 30 families in a south London borough. Disabil Soc 2006; 21(3): 259-272. DOI: https://doi.org/10.1080/09687590600617451

42. Nicolaidis $\mathrm{C}$, Raymaker D, McDonald K, et al. Comparison of healthcare experiences in autistic and non-autistic adults: a cross-sectional online survey facilitated by an academic-community partnership. J Gen Intern Med 2013; 28(6): 761-769. DOI: https://doi.org/10.1007/s11606-012-2262-7

43. Beange H, Bauman A. Caring for the developmentally disabled in the community. Aust Fam Physician 1990; 19(10): 1555-1558.

44. Prunchno RA, McMullen WF. Patterns of service utilisation by adults with a developmental disability: type of service makes a difference. Am J Ment Retard 2004; 109(5): 362-378.

45. Goldschmidt J. What happened to Paul? manifestation of abnormal pain response for individuals with autism spectrum disorder. Qual Health Res 2017; 27(8): 1133-1145. DOI: https://doi.org/10.1177/1049732316644415

46. Flood B, Henman MC. Case study: hidden complexity of medicines use: information provided by a person with intellectual disability and diabetes to a pharmacist. Br J Learn Disabil 2015; 43(3): 234-242. DOI: https://doi.org/ $10.1111 /$ bld.12121

47. Lennox TN, Nadkarni J, Moffat $P$, et al. Access to services and meeting the needs of people with learning disabilities. J Learn Disabil 2003; 7(1): 34-50. DOI: https://doi.org/10.1177/1469004703007001604

48. Wilkinson J, Dreyfus D, Bowen $D$, et al. Patient and provider views on the use of medical services by women with intellectual disabilities. J Intellect Disabil Res 2013; 57(11): 1058-1067. DOI: https://doi.org/10.1111/j.1365-2788. 2012.01606.x

49. Lees $\mathrm{C}$, Poole $\mathrm{H}$, Brennan $\mathrm{M}$, et al. Adults with learning disabilities experiences of using community dental services: service user and carer perspectives. Br J Learn Disabil 2017; 45(2): 114-120. DOI: https://doi.org/10.1111/bld. 12181

50. Mac Giolla Phadraig C, Dougall A, Stapleton S, et al. What should dental services for people with disabilities in Ireland be like? Agreed priorities from a focus group of people with learning disabilities. Br J Learn Disabil 2016; 44(4): 259-268. DOI: https://doi.org/10.1111/bld.12152

51. Hackett L, Shaikh S, Theodosiou L. Parental perceptions of the assessment of autistic spectrum disorders in a tier three service. Child Adolesc Ment Health 2009; 14(3): 127-132. DOI: https://doi.org/10.1111/j.1475-3588.2008. 00508.x

52. Walmsley J. An investigation into the implementation of annual health checks for people with intellectual disabilities. J Intellect Disabil 2011; 15(3): 157-166. DOI: https://doi.org/10.1177/1744629511423722 
53. Hale LA, Trip HT, Whitehead L, et al. Self-Management abilities of diabetes in people with an intellectual disability living in New Zealand. J Policy Pract Intellect Disabil 2011; 8(4): 223-230. DOI: https://doi.org/10.1111/j.17411130.2011.00314.x

54. Hall V, Conboy-Hill S, Taylor D. Using virtual reality to provide health care information to people with intellectual disabilities: acceptability, usability, and potential utility. J Med Internet Res 2011; 13(4): e91. DOI: https://doi.org/ 10.2196/jmir.1917

55. Boland M, Daly L, Staines A. Methodological issues in inclusive intellectual disability research: a health promotion needs assessment of people attending Irish disability services. J Appl Res Intellect Disabil 2008; 21(3): 199-209. DOI: https://doi.org/10.1111/j.1468-3148.2007.00404.x

56. Bollard M. Health promotion and intellectual disability: listening to men. Health Soc Care Community 2017; 25(1): 185-193. DOI: https://doi.org/10.1111/hsc.12291

57. Codling M. Helping service users to take control of their health. Learning Disability Practice 2015; 18(3): $26-31$. DOI: https://doi.org/10.7748/ldp.18.3.26.e1612

58. Miller E, Cooper S-A, Cook A, Petch A. Outcomes important to people with intellectual disabilities. J Policy Pract Intellect Disabil 2008; 5(3): 150-158. DOI: https://doi.org/10.1111/j.1741-1130.2008.00167.x

59. Raymaker DM, McDonald KE, Ashkenazy E, et al. Barriers to healthcare: instrument development and comparison between autistic adults and adults with and without other disabilities. Autism 2017; 21(8): 972-984. DOI: https:// doi.org/10.1177/1362361316661261

60. Lum M, Garnett M, O'Connor E. Health communication: a pilot study comparing perceptions of women with and without high functioning autism spectrum disorder. Res Autism Spectr Disord 2014; 8(12): 1713-1721. DOI: https:// doi.org/10.1016/j.rasd.2014.09.009

61. Greenwood NW, Dreyfus D, Wilkinson J. More than just a mammogram: breast cancer screening perspectives of relatives of women with intellectual disability. Intellect Dev Disabil 2014; 52(6): 444-455. DOI: https://doi.org/10. 1352/1934-9556-52.6.444

62. Truesdale-Kennedy M, Taggart L, Mcllfatrick S. Breast cancer knowledge among women with intellectual disabilities and their experiences of receiving breast mammography. J Adv Nurs 2011; 67(6): 1294-1304. DOI: https://doi.org/ 10.1111/j.1365-2648.2010.05595.x

63. Wilkinson JE, Deis CE, Bowen DJ, et al. 'It's easier said than done': perspectives on mammography from women with intellectual disabilities. Ann Fam Med 2011; 9(2): 142-147. DOI: https://doi.org/10.1370/afm.1231

64. Donner B, Mutter R, Scior K, et al. Mainstream in-patient mental health care for people with intellectual disabilities: service user, carer and provider experiences. J Appl Res Intellect Disabil 2010; 23(3): 214-225. DOI: https://doi. org/10.1111/j.1468-3148.2009.00527.x

65. Prangnell SJ, Green K. A cognitive behavioural intervention for dental anxiety for people with learning disabilities: a case study. Br J Learn Disabil 2008; 36(4): 242-248. DOI: https://doi.org/10.1111/j.1468-3156.2008.00510.x

66. Bell DM. Over the sea and far away: ways of overcoming some of the difficulties arising in work with adults with learning disabilities living in geographical isolation in the United Kingdom. Br J Learn Disabil 2005; 33(4): 180-187. DOI: https://doi.org/10.1111/j.1468-3156.2005.00312.x

67. Boada $L$, Parellada M. Seeing the doctor without fear: www.doctortea.org for the desensitization for medical visits in autism spectrum disorders. Rev Psiquiatr Salud Ment 2017; 10(1): 28-32. DOI: https://doi.org/10.1016/j.rpsm. 2016.09.005

68. Ferguson $M$, Jarrett $D$, Terras $M$. Inclusion and healthcare choices: the experiences of adults with learning disabilities. Br J Learn Disabil 2011; 39(1): 73-83.

69. Chinn D, Abraham E. Using 'candidacy' as a framework for understanding access to mainstream psychological treatment for people with intellectual disabilities and common mental health problems within the English Improving Access to Psychological Therapies service. J Intellect Disabil Res 2016; 60(6): 571-582. DOI: https://doi.org/10. 1111/jir.12274

70. Chilvers R, Gratton S, Bernard SH. Satisfaction with a child and adolescent mental health services (CAMHS) intellectual disability service. Adv Ment Health Intellect Disabil 2013; 7(1): 49-58. DOI: https://doi.org/10.1108/ 20441281311294701

71. O'Brien A, Rose J. Improving mental health services for people with intellectual disabilities: service users' views. Adv Ment Health Intellect Disabil 2010; 4(4): 40-47. DOI: https://doi.org/10.5042/amhid.2010.0674

72. Brolan CE, Boyle FM, Dean JH, et al. Health advocacy: a vital step in attaining human rights for adults with intellectual disability. J Intellect Disabil Res 2012; 56(11): 1087-1097. DOI: https://doi.org/10.1111/j.1365-2788. 2012.01637.x

73. Conder JA, Mirfin-Veitch BF, Gates S. Risk and resilience factors in the mental health and well-being of women with intellectual disability. J Appl Res Intellect Disabil 2015; 28(6): 572-583. DOI: https://doi.org/10.1111/jar.12153

74. Doody O, Slevin E, Taggart L. Families' perceptions of the contribution of intellectual disability clinical nurse specialists in Ireland. J Clin Nurs 2018; 27(1-2): e80-e90. DOI: https://doi.org/10.1111/jocn.13873

75. Barelds A, van de Goor I, van Heck G, et al. Quality of care and service trajectories for people with intellectual disabilities: defining the aspects of quality from the client's perspective. Scand J Caring Sci 2010; 24(1): 164-174. DOI: https://doi.org/10.1111/j.1471-6712.2009.00701.x

76. Baas K. Specialty: autism approaches need to be tailored to each person. Pa Nurse 2006; 61(1): 14-15

77. Owen $\mathrm{K}$, Evers $\mathrm{C}$, Hewitt $\mathrm{O}$. Experiences of using a health community team service for people with a learning disability. Learning Disability Practice 2018; 21(5): 37-42. DOI: https://doi.org/10.7748/ldp.2018.e1895

78. Ward RL, Nichols AD, Freedman RI. Uncovering health care inequalities among adults with intellectual and developmental disabilities. Health Soc Work 2010; 35(4): 280-290. DOI: https://doi.org/10.1093/hsw/35.4.280 
79. Saqr $Y$, Braun $E$, Porter $K$, et al. Addressing medical needs of adolescents and adults with autism spectrum disorders in a primary care setting. Autism 2018; 22(1): 51-61. DOI: https://doi.org/10.1177/1362361317709970

80. Royal College of General Practitioners. Urgent action needed to prevent more 'heart breaking' practice closures, says College. 2019; https://www.rcgp.org.uk/about-us/news/2019/may/urgent-action-needed-to-prevent-moreheart-breaking-practice-closures-says-college.aspx (accessed 17 Jun 2020).

81. Dysch C, Chung MC, Fox J. How do people with intellectual disabilities and diabetes experience and perceive their illness? J Appl Res Intellect Disabil 2012; 25(1): 39-49. DOI: https://doi.org/10.1111/j.1468-3148.2011.00641.x

82. Gerber AH, McCormick CEB, Levine TP, et al. Brief report: factors influencing healthcare satisfaction in adults with autism spectrum disorder. J Autism Dev Disord 2017; 47(6): 1896-1903. DOI: https://doi.org/10.1007/s10803-0173087-3 